\title{
Influence of Dental Hygienist's Job Satisfaction, Psychological Ownership, and Job Engagement on Job Performance
}

\author{
Ji-Hyeon Park ${ }^{1}$ and Soon-Ryun Lim ${ }^{2, \dagger}$ \\ 'Seran Dental Clinic, Bucheon 14570, ${ }^{2}$ Department of Dental Hygiene, Namseoul University, Cheonan 31020, \\ Korea
}

\begin{abstract}
Background: This study is to identify the factors that affect job satisfaction, psychological ownership, and job engagement of dental hygienists on job performance and use them as basic data for manpower management of dental hygienists.

Methods: The survey was conducted by 344 clinical dental hygienists working in dental medical institutions. The collected data is PASW Statistics ver. 20.0 was used to analyze.

Results: The job satisfaction level of the dental hygienist was $3.38 \pm 0.52$, and the question that 'I feel that my ability to solve problems has improved compared to the past.' was $3.92 \pm 0.80$. There were significant differences in job satisfaction, psychological ownership, and job engagement according to general characteristics in age, marriage, education, career, current work experience, and position. There were significant differences in job performance according to general characteristics in age, marriage, education, career, current work experience, position, and number of dental hygienists. Factors influencing job performance were practical activities, income, patient relations, absorption, vigor, dedication, and the number of dental hygienists.

Conclusion: Finding different ways to use psychological ownership and job engagement through the job satisfaction of a dental hygienist, and to and to utilize it as basic data for efficient manpower management through job performance.
\end{abstract}

Key Words: Dental hygienists, Job engagement, Job performance, Job satisfaction, Psychological ownership

\section{Introduction}

Due to the extension of life expectancy, people's demands for health and quality of life are increasing. The non-insurance burden ratio of dental hospitals and clinics was $50.4 \%$ for dental clinics and $62.6 \%$ for dental hospitals in 2018, and the non-insurance burden ratio exceeded $50 \%{ }^{1}$. As the public's burden of uninsured treatment increases, the demand for medical services from dental hospitals and clinics is also increasing.

The number of dental clinics opened and closed decreased from 1,023 to 586 in 2015 and 868 to 576 in 2018, but the ratio of closures to the number of openings increased from $57.28 \%$ in 2015 to $66.4 \%$ in $2018^{2}$. Excessive competition and economic recession are the causes of the closure, which are thought to have affected the dental business. Also, in the case of dental clinics, competition in rural and urban areas was fierce ${ }^{3)}$.

As excessive competition between dental hospitals and clinics intensifies, medical services have become more important, and the core of them will be human resources. The most important manpower in human resources is 
probably the dental hygienist. The role of the dental hygienist is also expanding to business and personnel management in addition to medical treatment. In this diversified role of dental hygienists, job performance will emerge as important.

Job performance evaluates job performance and includes task performance, service quality, and contextual performance ${ }^{4)}$. Various causes were suggested for job performance, and Park and Lee ${ }^{5)}$ stated that interpersonal relationship competency, self-regulation competency, and basic dental hygiene management competency affect the job performance of dental hygienists. Kim and $\mathrm{Han}^{6}{ }^{6}$ stated that patient orientation, relationship management ability, age, social awareness ability, and hospital type affect job performance. In the study of dental hygienists, the relationship between relationship ability and management ability was mainly studied with job performance.

In a study of volunteers in a restaurant company, job satisfaction was found to have an effect on job performance $^{7)}$, and the higher the job satisfaction, the higher the job performance ${ }^{8)}$. Among job satisfaction factors, patient relationship and autonomy were found to affect job performance $^{9)}$. Job satisfaction is judged to be one of the variables that affect job performance.

Cho et al. ${ }^{10)}$ found that psychological ownership and job satisfaction affect job performance. Kim et al. ${ }^{11)}$ found that job engagement, affects job performance. Roh and Yoon ${ }^{12)}$ found that job satisfaction and job engagement affect job performance. However, in dental hygiene research, there is insufficient research on the relationship between job performance, job satisfaction, psychological ownership, and job engagement.

In the meantime, the measurement tool used in the study on job satisfaction used a foreign tool targeting the general public or health care workers ${ }^{13)}$. Park and Lim $^{14)}$ developed a job satisfaction measurement tool for dental hygienists and included information on income, practice activity, working conditions, patient relations, professional satisfaction, and co-worker relations.

In this study, the factors of job satisfaction, psychological ownership, and job engagement of dental hygienists on job performance were identified using the job satisfaction measurement tool developed for dental hygienists. Through this, the dental hygienist's job performance, psychological ownership, and job engagement are raised to confirm the positive effect on job performance and use it as basic data for efficient manpower management.

\section{Materials and Methods}

\section{Study subjects}

The questionnaire was conducted from August 11, 2020 to August 18, 2020 for clinical dental hygienists working in dental institutions. This study is a method of directly filling out an online questionnaire. The Naver form was used, and the questionnaire was conducted only to those who revealed the purpose and purpose of the study and agreed to participate. To prevent duplication of questionnaires, one questionnaire per e-mail was allowed to be answered. The sample size for measuring job satisfaction and related factors is a two-sided test according to $G^{*}$ Power 3.1.9.2, the significance level $(\alpha)$ 0.05, the power $(1-\beta) 0.95$, the median effect size in the regression analysis of 0.15 , the random predictor variable It was calculated based on 22 items (general characteristics, job satisfaction, psychological ownership, job engagement, job performance). The minimum sample size was 230 . However, 347 subjects were recruited considering possible drop-outs. Those 3 subjects who did not complete the survey or showed unsatisfactory responses were excluded, and data of 344 subjects (recovery rate 95\%) were included in the final analysis.

\section{Study item}

\section{1) General characteristics}

The general characteristics consist of a total of 9 items. Age, marital, and education are 3 items in relation to individual characteristics. Regarding the characteristics of work, 6 items were composed of workplace, career, current work experience, position, number of dentists, and number of dental hygienists.

\section{2) Job satisfaction}

In the study of Park and Lim ${ }^{14)}$, a tool developed to measure job satisfaction of dental hygienists was used. 
This tool includes 6 practice activity indicating satisfaction with the dental hygienist's practical activities, 5 professional satisfaction items indicating the dental hygienist's occupational satisfaction, 3 income items indicating income satisfaction, and 4 items indicating satisfaction with the working conditions of dental hygienists, 3 items of patient relations indicating satisfaction in relationship with patients, 3 items of indicating co-worker relations who work with dental hygienists, were composed of a total of 24 items with 6 factors, each of which is Likert type on a 5-point scale, from 1 point of 'strongly disagree' to 5 points of 'strongly agree', the higher the score, the higher the job satisfaction. In the study of Park and Lim ${ }^{14)}$, the reliability of the measuring tool was 0.909 , and it was found to be 0.743 to 0.847 for each factor.

\section{3) Psychological ownership}

Psychological ownership was developed by Van Dyne and Pierce ${ }^{15)}$ and Yang ${ }^{16)}$ used the tools used in the study of dental hygienists. It consists of a total of 6 items, and each item is on a Likert-type 5-point scale, ranging from 1 point for 'strongly disagree' to 5 points for 'strongly agree'. In the positive study, the reliability Cronbach's $\alpha$ value was 0.906 .

\section{4) Job engagement}

For Job engagement, UWES-9 developed by Schaufeli et al. ${ }^{17)}$ was used as a tool used in the study of dental hygienists by Yang ${ }^{16)}$. This tool consists of 9 items with 3 factors: 3 items of vigor, 3 items of dedication, and 3 items of absorption. Each item is a Likert-type 5-point scale, ranging from 1 point for 'strongly disagree' to 5 points for 'strongly agree'. In the positive study, Cronbach's $\alpha$ values were 0.775 for vitality, 0.863 for commitment, and 0.831 for engagement.

\section{5) Job performance}

For job performance, tools developed by Tseng and $\mathrm{Fan}^{4)}$ and used in $\mathrm{Kim}^{18)}$ research were modified and used for dental hygienists. This tool consists of 11 items of 3 factors: 3 items of efficiency, 3 items of effectiveness, and 5 items of quality. Each item is a Likert-type 5-point scale, ranging from 1 point for 'strongly disagree' to 5 points for 'strongly agree', with higher scores indicating higher work performance. In $\mathrm{Kim}^{18)}$ study, the Cronbach's $\alpha$ value of job performance was 0.845 , the Cronbach's $\alpha$ value of efficiency by factor was 0.661 , the effectiveness was 0.780 , and the quality of work was 0.732 .

\section{Data analysis}

The collected data are PASW Statistics ver. 20.0 (IBM Corp., Armonk, NY, USA) was used for analysis. Descriptive statistical analysis was performed to find out the degree of job satisfaction of the study subjects. The t-test and ANOVA were conducted to find out job satisfaction, psychological ownership, job engagement, and job performance according to the characteristics of each factor, and the post-hoc test was verified with the Scheffe test. The relationship between job satisfaction, psychological ownership, job engagement, and job performance was analyzed using Pearson's correlation coefficient.

Stepwise multiple regression analysis is performed to determine the factors affecting job performance.

\section{Results}

\section{Job satisfaction level of dental hygienists}

Table 1 show job satisfaction level of dental hygienists. The job satisfaction level of dental hygienists was $3.38 \pm 0.52$. By factor, co-worker relationship was the highest at $3.65 \pm 0.68$ and income was lowest at $2.78 \pm 0.88$. As for the detailed items, 'I feel that my ability to solve problems has improved compared to the past' was the highest at $3.92 \pm 0.80$, and 'I am currently satisfied with my income' was the lowest at $2.75 \pm 0.99$.

\section{Job satisfaction, psychological ownership, job engagement, job performance according to general characteristics}

Table 2 shows job satisfaction, psychological ownership, job engagement, and job performance according to general characteristics. Job satisfaction showed a significant difference in age $(\mathrm{p}<0.001)$, and as a result of post-hoc analysis, it was highest in those over 40 years of age. There was a significant difference in marriage $(p<0.001)$, 
and the job satisfaction of married people was higher. There was a significant difference in education $(\mathrm{p}<$ 0.001 ), and as a result of post-hoc analysis, it was found to be higher over graduate school. There was a significant difference in career $(\mathrm{p}<0.001)$, and as a result of post-hoc analysis, 10 years or more was the highest. There was a significant difference in current work experience $(\mathrm{p}<$ 0.001 ), and as a result of post-hoc analysis, 5 years or more was the highest. There was a significant difference in position $(\mathrm{p}<0.001)$, and as a result of post-mortem analysis, the chief (responsible) dental hygienist was the highest.

Psychological ownership showed a significant difference in age $(\mathrm{p}<0.001)$, and as a result of post-hoc analysis, 20 to 29 years was the lowest. There was a significant difference in marriage $(\mathrm{p}<0.001)$, and job satisfaction among singles was high. There was a significant difference in educational $(\mathrm{p}=0.003)$, and as a result of post-hoc analysis, it was found to be higher over graduate school. There was a significant difference in career $(\mathrm{p}<$ 0.001 ), and as a result of post-hoc analysis, 10 years or more was the highest. There was a significant difference in

Table 1. Job Satisfaction Factors

\begin{tabular}{|c|c|c|}
\hline Sub-factor & Item & Value \\
\hline \multirow[t]{7}{*}{ Practice activity } & $\begin{array}{l}\text { I perform well in practice (medical affairs, administration, counseling, management } \\
\text { support). }\end{array}$ & $3.54 \pm 0.77$ \\
\hline & I feel that my ability to solve problems has improved compared to the past. & $3.92 \pm 0.80$ \\
\hline & I am satisfied that my opinions are reflected in the dental operation. & $3.28 \pm 0.92$ \\
\hline & $\begin{array}{l}\text { I am satisfied that I am in various practice (medical affairs, administration, counseling, } \\
\text { management support). }\end{array}$ & $3.30 \pm 0.87$ \\
\hline & I am good at dental care. & $3.57 \pm 0.90$ \\
\hline & I am satisfied that my opinion is reflected in the medical treatment. & $3.46 \pm 0.87$ \\
\hline & Subtotal & $3.51 \pm 0.62$ \\
\hline \multirow[t]{6}{*}{ Professional satisfaction } & I feel quite proud to be a dental hygienist. & $3.47 \pm 0.90$ \\
\hline & $\begin{array}{l}\text { If my child were interested in dental hygiene, I would encourage him/her to pursue a } \\
\text { dental career. }\end{array}$ & $3.25 \pm 1.08$ \\
\hline & I think dental hygienists are professional. & $3.83 \pm 0.93$ \\
\hline & I will continue my dental hygienist until conditions are met. & $3.60 \pm 1.00$ \\
\hline & I think dental hygienists are more differentiated than other occupations. & $3.45 \pm 0.97$ \\
\hline & Subtotal & $3.52 \pm 0.75$ \\
\hline \multirow[t]{4}{*}{ Income } & I am currently satisfied with my income. & $2.75 \pm 0.99$ \\
\hline & I am very pleased with my income compared to other dental hygienist. & $2.81 \pm 1.00$ \\
\hline & My income compares favorably to that of other professionals. & $2.77 \pm 1.04$ \\
\hline & Subtotal & $2.78 \pm 0.88$ \\
\hline \multirow[t]{5}{*}{ Working conditions } & Our dental clinic working hours are sufficient for leisure. & $3.17 \pm 1.08$ \\
\hline & I am happy with the separation between working hours and personal hours after work. & $3.54 \pm 0.96$ \\
\hline & I have plenty of time to improve my clinical skills. & $3.26 \pm 0.89$ \\
\hline & I have enough time to perform my practice at the time of treatment. & $3.28 \pm 0.92$ \\
\hline & Subtotal & $3.31 \pm 0.74$ \\
\hline \multirow[t]{4}{*}{ Patient relations } & I feel that patients respect me. & $3.38 \pm 0.86$ \\
\hline & I feel intimate with the patients. & $3.46 \pm 0.84$ \\
\hline & I am satisfied with the patient's help. & $3.80 \pm 0.75$ \\
\hline & Subtotal & $3.55 \pm 0.66$ \\
\hline \multirow[t]{4}{*}{ Co-worker relations } & $\begin{array}{l}\text { The members (partners, bosses, and juniors) who work with me have high medical } \\
\text { performance. }\end{array}$ & $3.61 \pm 0.85$ \\
\hline & Good teamwork between members (partners, bosses, and juniors) working with me. & $3.63 \pm 0.81$ \\
\hline & The members (colleagues, bosses, juniors) who work with me favorably do what I do. & $3.73 \pm 0.84$ \\
\hline & Subtotal & $3.65 \pm 0.68$ \\
\hline Total & & $3.38 \pm 0.52$ \\
\hline
\end{tabular}

Values are presented as mean \pm standard deviation. 


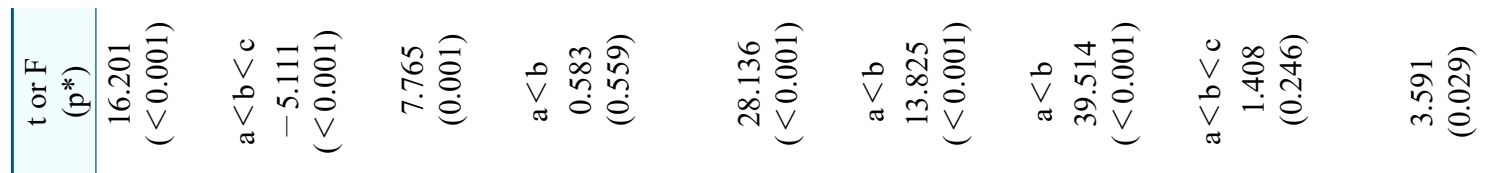

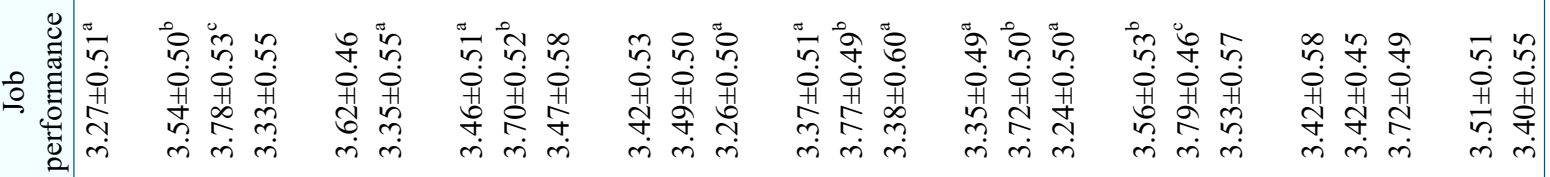

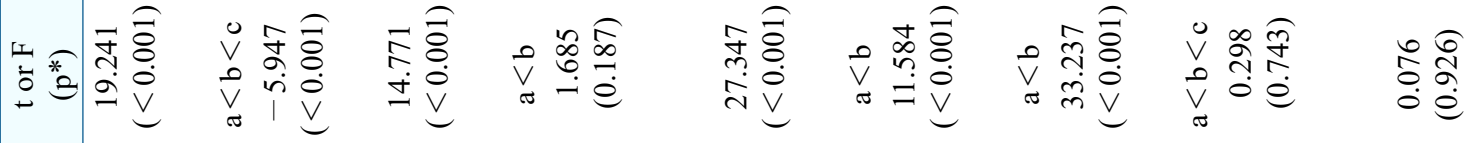

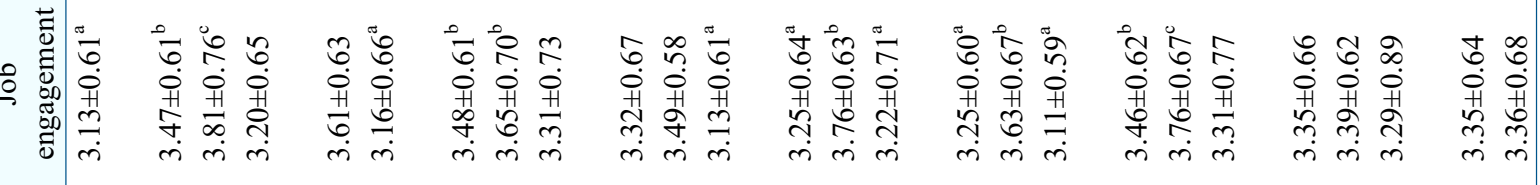

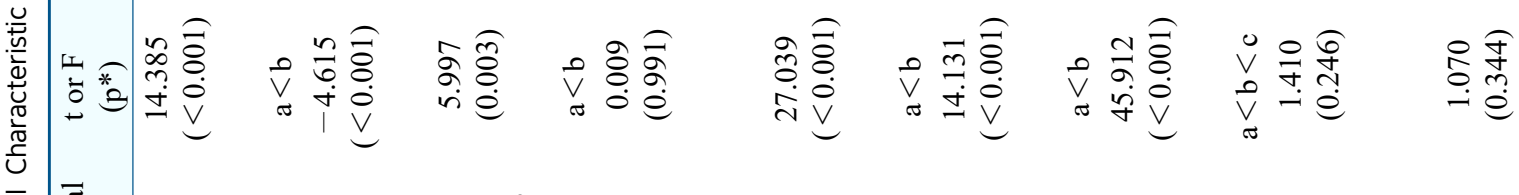

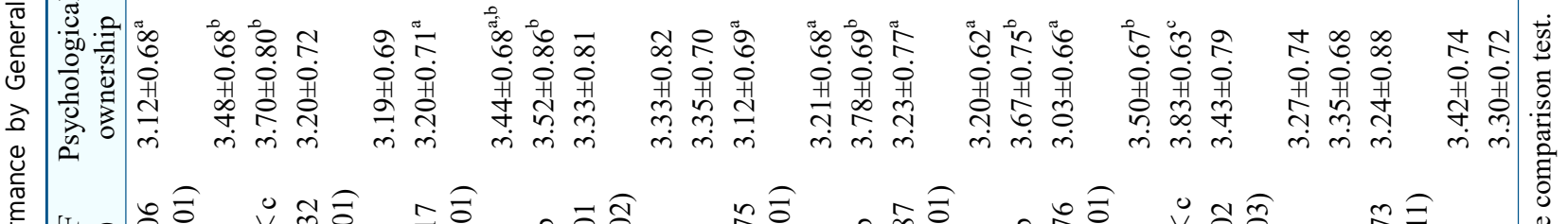

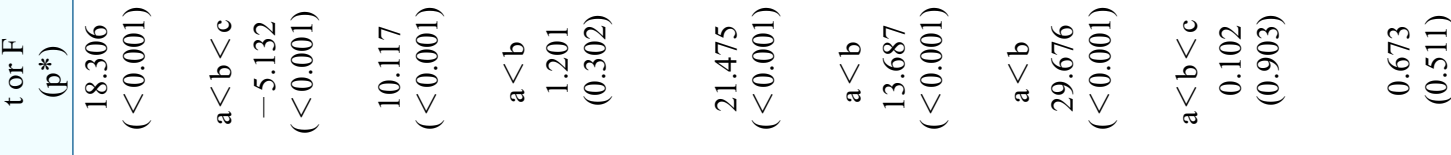

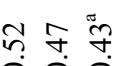

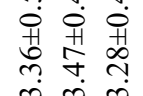

ก๊ ते

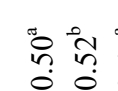
$=8$ क
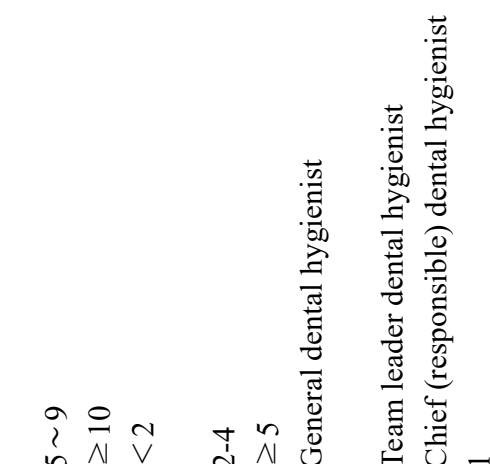

ติฮి

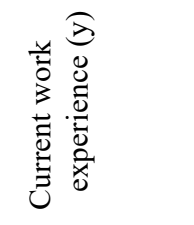

| II 
current work experience $(\mathrm{p}<0.001)$, and as a result of post-hoc analysis, 5 years or more was the highest. There was a significant difference in position $(\mathrm{p}<0.001)$, and as a result of post-hoc analysis, the chief (responsible) dental hygienist was the highest.

There was a significant difference in age $(\mathrm{p}<0.001)$ in job engagement, and as a result of post-hoc analysis, 40 years of age or older was the highest. There was a significant difference in marriage $(\mathrm{p}<0.001)$, and there was a significant difference in education $(\mathrm{p}<0.001)$. As a result of post-hoc analysis, it was found to be higher graduate school. There was a significant difference in career $(\mathrm{p}<0.001)$, and as a result of post-hoc analysis, 10 years or more was the highest. There was a significant difference in current work experience $(\mathrm{p}<0.001)$, and as a result of post-hoc analysis, 5 years or more was the highest. There was a significant difference in position $(\mathrm{p}<$ 0.001 ), and as a result of post-hoc analysis, it was highest in the chief (responsible) hygienist.

There was a significant difference in job performance by age $(\mathrm{p}<0.001)$, and as a result of post-hoc analysis, the age of 40 and older showed the highest. There was a significant difference in marriage $(\mathrm{p}<0.001)$, and there was a significant difference in education $(\mathrm{p}=0.001)$. As a result of the post-hoc analysis, over graduate school was the highest. There was a significant difference in career $(\mathrm{p}<0.001)$, and as a result of post-hoc analysis, 10 years or more was the highest. There was a significant difference in current work experience $(\mathrm{p}<0.001)$, and as a result of post-hoc analysis, 5 years or more was the highest. There was a significant difference in position $(\mathrm{p}<$ 0.001 ), and as a result of post-hoc analysis, it was highest in the chief (responsible) hygienist. There was a significant difference in number of dental hygienists $(p=$ 0.029), and post-hoc analysis showed no difference.

\section{Correlation between job satisfaction, psychological ownership, job engagement, and job performance}

Table 3 shows the correlations between job satisfaction, psychological ownership, job engagement, and job performance of the study subjects. Job performance was positively correlated with job satisfaction, psychological ownership and job engagement.

Table 3. Correlation between Job Satisfaction, Psychological Ownership, Job Engagement, Job Performance

\begin{tabular}{lcccc}
\hline \multicolumn{1}{c}{ Characteristic } & Job satisfaction & Psychological ownership & Job engagement & Job performance \\
\hline Job satisfaction & 1 & & & \\
Psychological ownership & $0.697^{* *}$ & 1 & 1 & 1 \\
Job engagement & $0.782^{* *}$ & $0.713^{* *}$ & $0.686^{* *}$ & 1 \\
Job performance & $0.652^{* *}$ & $0.601^{* *}$ & \\
\hline
\end{tabular}

$* * \mathrm{p}<0.01$ by pearson's correlation analysis.

Table 4. Factors affecting Job Performance

\begin{tabular}{lcccrrr}
\hline \multicolumn{1}{c}{ Characteristic } & $\mathrm{B}$ & $\mathrm{SE}$ & $\beta$ & $\mathrm{t}$ & $\mathrm{p}$-value & Tolerance $^{\mathrm{a}}$ \\
\hline (constants) & 0.936 & 0.118 & & 7.915 & $<0.001$ & \\
Practice activity & 0.428 & 0.037 & 0.493 & 11.531 & $<0.001$ & 0.549 \\
Absorption & 0.112 & 0.037 & 0.144 & 3.028 & 0.003 & 0.445 \\
Vigor & 0.124 & 0.034 & 0.186 & 3.653 & $<0.001$ & 0.385 \\
Income & -0.071 & 0.023 & -0.116 & -3.065 & 0.002 & 0.700 \\
Number of dental hygienists $(4>$ above $=1)$ & -0.109 & 0.037 & -0.096 & -2.991 & 0.003 & 0.974 \\
Dedication & 0.074 & 0.036 & 0.109 & 2.075 & 0.039 & 0.364 \\
Patient relations & 0.068 & 0.034 & 0.084 & 2.012 & 0.045 & 0.572 \\
& $\mathrm{R}=0.814, \mathrm{R}^{2}=0.663$, adjusted $\mathrm{R}^{2}=0.656, \mathrm{~F}=94.388, \mathrm{p}<0.001$ & \multicolumn{5}{c}{} \\
\hline
\end{tabular}

Excluded variables: age (y), marriage, education, workplace, career (y), current work experience (y), position, number of dentists, professional satisfaction, working conditions, co-worker relations, psychological ownership, efficiency, effectiveness, quality. ${ }^{\mathrm{a}} \mathrm{p}$-value by stepwise multiple regression analysis at $\alpha=0.05$. 


\section{Factors affecting job performance}

Table 4 shows a stepwise multiple regression analysis was performed with job performance as a dependent variable and general characteristics, job satisfaction, psychological ownership, and job engagement as independent variables. Regarding the independence of the residuals, the Durbin-Watson test coefficient was 2.000, so there was no problem of autocorrelation, and the tolerance limit was 0.364 to 0.974 , indicating that the above model was significant $(\mathrm{F}=94.388, \mathrm{p}<0.001)$ (Table 4). The independent variables that had a significant effect on the job performance of dental hygienists were practice activity $(\beta=0.493, \mathrm{t}=11.531, \mathrm{p}<0.001)$, absorption $(\beta=0.144$, $\mathrm{t}=3.028, \mathrm{p}=0.003)$, and vigor $(\beta=0.186, \mathrm{t}=3.653, \mathrm{p}<$ $0.001)$, income $(\beta=-0.116, \mathrm{t}=-3.065, \mathrm{p}=0.002)$, number of dental hygienists $(\beta=-0.096, \mathrm{t}=-2.991, \mathrm{p}=0.003)$, dedication $(\beta=0.109, \mathrm{t}=2.075, \mathrm{p}=0.039)$ and patient relations $(\beta=0.084, \mathrm{t}=2.012, \mathrm{p}=0.045)$, and the explanatory power was $65.6 \%$.

\section{Discussion}

As a result of analyzing the job satisfaction of dental hygienists in this study, the overall average was 3.38 points, and although the measurement tools were different, Park and Cho ${ }^{19)}$ showed similar results, with 3.30 points and Kim et al. ${ }^{20)} 3.29$ points. In this study, job satisfaction by factor was found to be the lowest at 2.78 points in income, which coincided with the lowest score of 2.87 points in Park and $\mathrm{Cho}^{19)}$ study and 2.63 points in remuneration in the study of Yoon et al. ${ }^{21)}$. As for job satisfaction by item, the question 'I feel that my ability to solve problems has improved compared to the past.' was the highest with 3.92 points, and 'I am currently satisfied with my income' was the lowest with 2.75 points. In the study of Park and Cho ${ }^{19)}$ 'My income compares favorably to that of other professionals.' with 2.72 points, and in the study of Kim et al. ${ }^{20)}$, 'I am satisfied with my current salary' was the lowest with 2.68 points. appeared similar to what appeared. The salary and income factors of dental hygienists were lower than the average job satisfaction. In the study of Park and Lim ${ }^{14)}$, the results are contradictory to the results of those who said that they were satisfied with their salaries compared to those of similar age groups and other occupations in terms of monetary compensation. Also, I think that I am proud to work as a dental hygienist or work professionally, but I think that the treatment for him is not satisfactory, so the income part is the lowest among the job satisfaction factors. It would be nice if the income of dental hygienists would increase every year, but if not, improving working conditions such as working four days a week or providing accommodations, or providing opportunities to improve welfare or develop skills such as support for tuition or seminar expenses can also reduce dissatisfaction with income. I think it can be offset.

As a result of analyzing job satisfaction according to general characteristics, when you are over 40, when you are married, when you are enrolled in graduate school or higher, when your total work experience is more than 10 years, when you have more than 5 years of current work experience, when you are a senior (responsible) dental hygienist appeared high. Han et al. ${ }^{22)}$ said that the older the age and the more experience, the higher the job satisfaction. Park and $\mathrm{Cho}^{19)}$ are 30 to 39 years old, married, have a master's degree or higher, and have more than 10 years of total work experience, working at their current job. This study showed similar results when the experience was more than 5 years and the senior (responsible) dental hygienist was higher. If you have a lot of work experience and work for a long time in one workplace, you will have a variety of tasks and autonomy based on mutual trust. In addition, it is thought that the skill level of the job according to the age had an effect on the confidence and efficiency. This is considered to have had an impact on the job satisfaction of dental hygienists.

As a result of analyzing psychological ownership according to general characteristics, when you are over 40 , when you are single, when you attend graduate school or more, when your total work experience is more than 10 years, when your current job experience is more than 5 years, when you are a senior (responsible) dental hygienist appeared high when Yoo et al. ${ }^{23)}$ for nurses was higher when they were 31 years of age or older, in graduate school or higher, and when they had more than 10 years of experience. In the case of a dental hygienist, a dental hygienist's psychological ownership means that the object 
of an individual's possession is his or her own. In the case of dental hygienists, if they have more than 10 years of work experience, they are often in charge of administrative or administrative duties. Considering that there are many cases of dental hygienists in charge at dental clinics, the responsibility for their work is a psychological sense of ownership. is considered to have influenced.

As a result of analyzing job engagement according to general characteristics, when you are over 40, when you are married, when you attend graduate school or more, when you have 10 years of total work experience, when you have more than 5 years of current work experience, when you are a senior (responsible) dental hygienist appeared high. Although the occupational groups are different, Moon et al. ${ }^{24)}$ study on nurses showed that those in their 40 s or older, head nurses or chief nurses, and those with more than 10 years of experience showed higher job engagement, similar to this study. In the case of the chief (responsible) dental hygienist, since autonomy is given to their work, vitality, dedication, and immersion among the engagement for their job must have been high, and it is thought that the responsibility for their work was higher than that of general dental hygienists.

As a result of analyzing job performance according to general characteristics, when you are over 40 , when you are married, when you are enrolled in graduate school or higher, when you have more than 10 years of total work experience, when you have more than 5 years of current work experience, when you are a senior (responsible) dental hygienist appeared high. There was also a significant difference in the number of dental hygienists. Kim and $\mathrm{Kim}^{25)}$ found that the older the age, the higher the job performance ability, the higher the age, the higher the job performance, the higher the job performance, the higher the bachelor's degree or higher, the more total or current work experience, and the higher the position. Kim and $\mathrm{Han}^{6)}$ showed similar results as in this study, showing that they were 36 years old or older, 11 years of work experience or more, and the reception and counseling areas or management and administration areas were high, and the position was higher in the case of the head of the department. The higher the age, experience, or position, the higher the role will be as a manager at the dental clinic.
Job performance is judged to be higher if the goal for the job is achieved or if the organization feels that the organization is well managed.

Factors affecting job performance were practice activity, income, and patient relations among the factors of job satisfaction. It was the absorption, vigor, and dedication of the job engagement and the number of dental hygienists in general characteristics. Roh and Yoon ${ }^{12)}$, who studied food service workers in other occupations, showed that job satisfaction and job engagement had an effect on job performance, as there was insufficient research on job performance of dental hygienists. In the study of $\mathrm{Ha}$ and Lee $^{7)}$, job satisfaction was found to have an effect on job performance. Kim et al. ${ }^{11)}$ found that job engagement affects job performance. Although the occupations were different, the results were similar to those of this study, and it was confirmed that job satisfaction and job engagement were the leading variables in job performance. Both antecedent factors are thought to be one of the most human resource management factors for job performance.

In this study, the effects of job satisfaction, psychological ownership, and job engagement on job performance were studied. There have been many studies on job satisfaction in the dental hygiene field, but relatively few studies on psychological ownership, job engagement, and job performance have made it difficult to compare with previous studies. In this study, it seems that future research should be continuously conducted. Through this, we find various ways to promote psychological ownership through job satisfaction of dental hygienists or to increase job engagement, and through this, we find a positive effect on job performance and use it as basic data for efficient manpower management through long-term service of dental hygienists.

\section{Notes}

\section{Conflict of interest}

No potential conflict of interest relevant to this article was reported.

\section{Ethical approval}

This study was approved by the Institutional Review 
Board of Namseoul University (IRB No. 202003-003).

\section{Author contributions}

Conceptualization: Ji-Hyeon Park and Soon-Ryun Lim. Data acquisition: Ji-Hyeon Park. Formal analysis: Ji-Hyeon Park. Supervision: Soon-Ryun Lim. Writing-original draft: Ji-Hyeon Park. Writing-review \& editing: Ji-Hyeon Park.

\section{ORCID}

Ji-Hyeon Park, https://orcid.org/0000-0002-3654-8911

Soon-Ryun Lim, https://orcid.org/0000-0002-5654-1995

\section{References}

1. Jeon JE, Lee GY, Kim YM, et al.: 2019 year book of the Korean dentistry. Health Policy Institute, Seoul, p. 105, 2020 .

2. Health Insurance Review \& Assessment Service: Statistical publications other statistics opening and closing of medical institutions (2015-2019). Retrieved July 5, 2021, from: https://opendata.hira.or.kr/op/opc/selectStcPblc.do?sno=127 03\&odPblcTpCd=004\&searchCnd=\&searchWrd=\&pageInd ex=1(2020, March 9).

3. Kim PJ: The analysis of industrial concentration in medical clinic, dental clinic, and oriental clinic. JKAIS 20: 401-408, 2019.

https://doi.org/10.5762/KAIS.2019.20.4.401

4. Tseng FC, Fan YJ: Exploring the influence of organizational ethical climate on knowledge management. JBE 101: 325-342, 2011. https://doi.org/10.1007/s10551-010-0725-5

5. Park JH, Lee YH: Influence of dental hygienists' core competencies on job performance. J Dent Hyg Sci 17: 142-149, 2017.

https://doi.org/10.17135/jdhs.2017.17.2.142

6. Kim YJ, Han GS: Relationships among emotional leadership, commitment, patient orientation, and job performance in dental hygienists. J Dent Hyg Sci 15: 551-559, 2015. https://doi.org/10.17135/jdhs.2015.15.5.551

7. Ha JM, Lee EM: A study on the effects of positive psychological capital on employee satisfaction and job performance. IJTHR 32: 81-94, 2018.
https://doi.org/10.21298/IJTHR.2018.12.32.12.81

8. Seong MG, Kim YR: Comparison of job satisfaction, turnover intention, and job performance by dental hygienists' clinical assistance and preventive work. J Korean Soc Dent Hyg 19: 221-229, 2019. https://doi.org/10.13065/jksdh.20190018

9. Lee BH, Kim JS: The relationship between coaching behaviors of dental managers, job satisfaction and job performance of dental hygienists. KJHSM 6: 121-130, 2012. https://doi.org/10.12811/kshsm.2012.6.4.121

10. Cho HY, Kim K, Park KY: An exploratory analysis of antecedents and consequences of psychological ownership: focused on hotel employee. KJHA 20: 75-97, 2011.

11. Kim HS, Kim MS, Koo DW: The effect of general manager's transformational leadership in hotel on foodservice employee's job engagement, job performance, and turnover intention. Food Serv Ind J 9: 29-43, 2013. https://doi.org/10.22509/kfsa.2013.9.3.003

12. Roh YW, Yoon HH: The effect of supervisors' ethical leadership on job satisfaction, job engagement and job performance of foodservice employees. KJHA 26: 1-19, 2017. https://doi.org/10.24992/KJHT.2017.07.26.05.01.

13. Lim SR, Park JH: A systematic literature review on job satisfaction of dental hygienist. JCIT 9: 123-135, 2019. https://doi.org/10.22156/CS4SMB.2019.9.1.123

14. Park JH, Lim SR: Development of job satisfaction scale for dental hygienist. J Korean Soc Dent Hyg 20: 913-924, 2020. https://doi.org/10.13065/jksdh.20200084

15. Van Dyne L, Pierce JL: Psychological ownership and feelings of possession: three field studies predicting employee attitudes and organizational citizenship behavior. J Organ Behav 25: 439-459, 2004. https://doi.org/10.1002/job.249

16. Yang JA: Development and evaluation of scale of long-term employment for dental hygienist. Unpublished doctoral dissertation, Namseoul University, Cheonan, 2018.

17. Schaufeli WB, Salanova M, González-romá V, Bakker AB: The measurement of engagement and burnout: a two sample confirmatory factor analytic approach. J Happiness Stud 3: 71-92, 2002.

18. Kim KS: Job performance determinants model of the social workers in public sector - focused on mediating effects of the self efficacy, the intrinsic job motivation. Unpublished 
doctoral dissertation, Ewha Womans University, Seoul, 2016.

19. Park JH, Cho YS: Effect of job satisfaction on turnover intention and intention to stay in dental hygienists. J Korean Soc Dent Hyg 20: 95-106, 2020. https://doi.org/10.13065/jksdh.20200010

20. Kim NS, Yoon NN, Kim YH, Park JH. Kim HJ, Lee JH: The effect of dental hygienist's work environment on job satisfaction and organizational commitment. J Korean Soc Dent Hyg 18: 153-164, 2018.

https://doi.org/10.13065/jksdh.2018.18.02.153

21. Yoon NN, Lee JY, Yu BC: The correlations between psychological empowerment, leader-member exchange (LMX) and job satisfaction in dental hygienists. J Korean Soc Dent Hyg 17: 405-418, 2017.

https://doi.org/10.13065/jksdh.2017.17.03.405
22. Han JH, Song KS, Shin SJ: Factors affecting job satisfaction of clinical dental hygienists. J Dent Hyg Sci 18: 374-379, 2018.

https://doi.org/10.17135/jdhs.2018.18.6.374

23. Yoo MR, Yoo JA, Kim YM: Study for professionalism, organizational citizenship behavior, psychological ownership of nurse officers. J Korean Acad Nurs Adm 8: 290-300, 2012. https://doi.org/10.11111/jkana.2012.18.3.290

24. Moon IO, Park SK, Jung JM: Effects of resilience on work engagement and burnout of clinical nurses. J Korean Acad Nurs Adm 19: 525-535, 2013.

https://doi.org/10.11111/jkana.2013.19.4.525

25. Kim JH, Kim HJ: Job performance and Job performance rate of clinical dental hygienist. AJMAHS 7: 431-440, 2017. https://doi.org/10.35873/ajmahs.2017.7.5.039 